\title{
Development of a standardized in-hospital cardiopulmonary resuscitation set-up
}

\author{
TAE SOON PARK, JE HYEOK OH, CHAN WOONG KIM, DONG HOON LEE, JUN YOUNG HONG, SUNG EUN KIM \\ Department of Emergency Medicine, College of Medicine, Chung-Ang University, Seoul, Republic of Korea
}

\author{
Corresponding author \\ Je Hyeok Oh \\ Department of Emergency Medicine, College of Medicine \\ Chung-Ang University \\ 84 Heukseok-ro, Dongjak-gu, Seoul, Republic of Korea 06974 \\ Phone/Fax: 82-2-6299-1820, 82-2-6299-2558 \\ E-mail: jehyeokoh@cau.ac.kr
}

\section{ABSTRACT}

Objective. This study evaluated whether chest compression in a standardized inhospital cardiopulmonary resuscitation (CPR) set-up can be performed as effectively as when the rescuer is kneeling beside the patient lying on the floor. Specifically, the in-hospital test was standardized according to the rescuers' average knee height.

Methods. Experimental intervention (test 1) was a standardized, in-hospital $C P R$ set-up: first, the bed height was fixed at 70 $\mathrm{cm}$. Second, the height difference between the bed and a step stool was set to the average knee height of the CPR team members $(45 \mathrm{~cm})$. Control intervention (test 2) was kneeling on floor. Thirty-eight medical doctors on the CPR team each performed 2 minutes of chest compressions in test 1 and 2 in random order (cross-over trial). A Little Anne was used as a simulated patient who had experienced cardiac arrest. Chest compression parameters, such as average depth and rate, were measured using an accelerometer device.

Results. In all tests, the average depths were those recommended in the most recent CPR guidelines (50-60 mm); there were no significant differences between Tests 1 and $2(53.1 \pm 4.3 \mathrm{~mm}$ vs. $52.6 \pm 4.8 \mathrm{~mm}$, respectively; $\mathrm{p}=0.398)$. The average rate in Test 2 (119.1 \pm 12.4 numbers $/ \mathrm{min})$ was slightly faster than that in Test 1 (116.4 \pm 10.2 numbers $/ \mathrm{min} ; \mathrm{p}=0.028)$. No differences were observed in any other parameters.

Conclusions. Chest compression quality in our standardized in-hospital CPR set-up was similar with that performed in a kneeling position on the floor.

Trial Registration: Clinical Research Information Service: KCT0001599

Key words: beds, cardiopulmonary resuscitation, posture

\section{INTRODUCTION}

High-quality cardiopulmonary resuscitation (CPR), especially high-quality chest compression, is a key factor in patient survival after cardiac arrest. (1) The 2015 guidelines recommend performing chest compression while kneeling by the victim's side. (2) The kneeling position is easy to assume when the victim is lying on the floor. However, most in-hospital CPR is performed with the patient lying in bed. In such cases, the height of the rescuer relative to the patient's position may influence the quality of CPR. (3)

Several studies have evaluated the effects of the rescuer's height on the quality of CPR. (4-7) They have found that kneeling beside a patient lying on the floor is the best position in which to perform high-quality chest compression, and that adjusting the bed height to the rescuer's knee level enhances the quality of chest compression when the patient is lying in bed.

Considering these results, two solutions for high-quality in-hospital chest compression have been suggested: (1) kneeling on the bed when performing CPR, and (2) adjusting the bed to the height of the rescuer's knee during in-hospital CPR. $(3,8)$ Although these solutions have been shown to be effective, $(9,10)$ they are difficult to apply in practice, because most hospital beds are not wide enough for a rescuer to kneel beside the patient, and adjusting the bed height each time the rescuer is changed due to fatigue may increase hands-off time. Another solution is to use a step stool. However, this results in an $18 \%$ increase in incomplete recoil, despite increasing compression depth by $4 \mathrm{~mm}$. (11)

If it were possible to standardize the height of the rescuer in relation to the patient's position, clinicians could provide highquality chest compression during in-hospital CPR, regardless of individual rescuer characteristics. Indeed, one examination of published studies revealed no significant difference in the average chest compression depth when the bed height was within $10 \mathrm{~cm}$ of the rescuer's knee height. (5) We measured the total heights and knee heights of the 20 CPR team members in our hospital. Although their heights ranged from 157 to $182 \mathrm{~cm}$ (difference: 25 $\mathrm{cm})$, their knee heights only ranged from 39 to $52 \mathrm{~cm}$ (difference: $13 \mathrm{~cm}$ ). Therefore, if the in-hospital CPR set-up were standardized with reference to the $\mathrm{CPR}$ team members' average knee height, the bed height could be placed within $10 \mathrm{~cm}$ of the individual rescuers' knee heights (figure 1A). We hypothesized that chest compression in this standardized in-hospital CPR set-up would be as effective as when kneeling beside a patient lying on the floor.

\section{METHODS}

\section{Study Design}

This was a prospective, cross-over, randomised, simulation trial (figure 2). Two different experiments (Tests 1 and 2) were conducted randomly. The participants were randomized into Groups A and B using randomization lists that were created by assigning random number sequences to six permuted blocks ( $\mathrm{AABB}, \mathrm{ABAB}$, $\mathrm{ABBA}, \mathrm{BBAA}, \mathrm{BABA}$, and $\mathrm{BAAB})$ in a web-based program. (12) The randomization lists were created on 17 August 2015. Thirty-minute rest periods were permitted between the tests. The study was approved by our hospital's Institutional Review Board (IRB) and registered to the clinical trial registry platform. Informed consent was confirmed by the IRB. 


\section{Study Design and Population}

This study was conducted in the emergency department of an academic hospital between September 2015 and January 2016. The standardized in-hospital CPR set-up comprised a 70-cm-high bed, a simulated patient who had experienced cardiac arrest, and a 25-cm-high step stool. The height of the bed was set to $70 \mathrm{~cm}$ (the average mid-thigh height of the rescuers) for the following reasons. First, a survey indicated that the doctors in our hospital feel more comfortable during airway-related procedures (e.g. endotracheal intubation or bag mask ventilation) with the patient lying at mid-thigh height than with the patient at knee-height. (13) Second, the average mid-thigh height of the 33 medical doctors in our hospital was $71.2 \pm 4.0$ $\mathrm{cm}$. (13)

We measured the knee heights of the 20 sample rescuers on our hospital's CPR team who had not participated in the present study to determine the average knee height of the rescuers. We defined knee height as the distance from the floor to the tibial tuberosity in an erect position. (10) Thirteen men and seven women were selected. The average height of the sample rescuers was $170.4 \pm 7.3 \mathrm{~cm}$ (range: $25 \mathrm{~cm}$ ), and their average knee height was $45.7 \pm$ $3.0 \mathrm{~cm}$ (range: $13 \mathrm{~cm}$ ). For convenience, we assumed an average knee height of $45 \mathrm{~cm}$ to manufacture the step stool. Therefore, the height of the step stool was $25 \mathrm{~cm}$ (i.e. $25=70-45$ [the height of the bed minus the average knee height]).

A Little Anne (Laerdal Medical, Stavanger, Norway) was used as a simulated adult patient who had experienced cardiac arrest. Chest compression data were measured using a CPRmeter (Laerdal Medical), and the Q-CPR review program (ver. 3.1; Laerdal Medical). In such cases, it is possible to overestimate the compression depth, because the CPRmeter measures this value using an accelerometer. (14) For this reason, our set-up did not include any mattress. In addition, the bed was made from a plywood sheet $(50 \mathrm{~cm}$ wide $\times 60 \mathrm{~cm}$ long $\times 70 \mathrm{~cm}$ high) to prevent bed frame deflection during chest compression. (15)

Medical doctors who met the inclusion criteria participated in the study after providing written informed consent. The inclusion criteria were as follows: (1) membership of our hospital's CPR team; and (2) certification as a basic life support (BLS) instructor, or completion of all BLS courses for healthcare providers within the 2 years prior to the study. Our hospi-

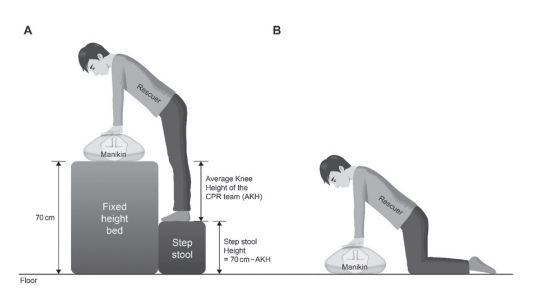

Figure 1. Study design: Standardized in-hospital cardiopulmonary resuscitation $(C P R)$ set-up $(A)$ versus Kneeling on the floor (B).

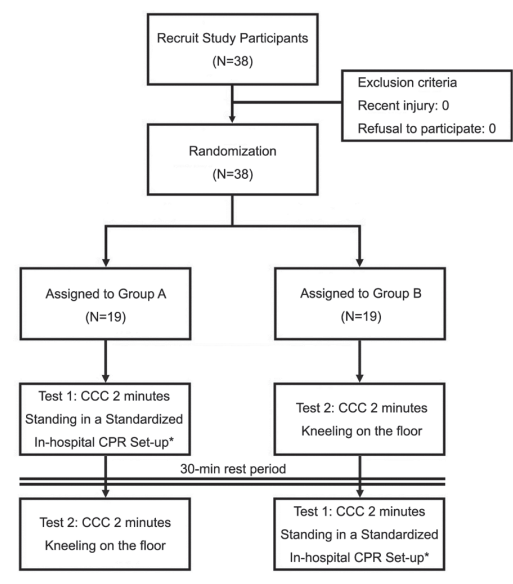

Figure 2. Study flow diagram

CCC, continuous chest compression; $C P R$, cardiopulmonary resuscitation.

*Standardized In-hospital CPR set-up: standardized in-hospital cardiopulmonary resuscitation set-up with reference to the rescuers' average knee height $(45 \mathrm{~cm})$

tal CPR team includes attending, resident, and intern physicians from the following departments: internal medicine, surgery, neurosurgery, emergency medicine, anaesthesiology, and pediatrics. The exclusion criteria were: (1) inability to perform CPR because of a recent injury, and (2) refusal to participate in the study or provide informed consent.

The sample size was calculated on the basis of a primary outcome variable of chest compression depth. We set the two-sided significance level to 0.05 , and the power of the test to $80 \%$. The average compression depth was determined to be $53.9 \pm 5.8$ $\mathrm{mm}$, based on data from a previous study. (10) Because no reference data on the average depth in a standardized in-hospital CPR set-up were available, we arbitrarily set the allowable difference in average depth between Tests 1 and 2 to $5 \%$ of this previous average depth $(2.695 \mathrm{~mm})$. Using a web program, we determined that the minimum number of participants in each group was 19 (sample size calculator: two crossover-sample means; hypothesis: twosided equality). (16)

\section{Study Protocol}

In Test 1, the participants performed continuous chest compression for 2 minutes using the standardized in-hospital CPR set-up (figure 1A). In Test 2, participants performed continuous chest compression for 2 minutes while kneeling on the floor beside the Little Anne with a CPRmeter (figure 1B). No ventilation was performed in either test.

The participants assigned to Group A performed Test 1 first, whereas those assigned to Group B performed Test 2 first (figure 2). A 30-min rest period was permitted between the tests. In addition, we allowed the participants 1-minute practice time to familiarize themselves with the CPRmeter before the tests.

\section{Outcome Variables}

The average depth $(\mathrm{mm})$ measured by the CPRmeter was used as the primary outcome variable. In addition, we selected the number of compressions, average compression rate $(\mathrm{n} / \mathrm{min})$, percentage of complete release, adequate depth achievement, and flow time as secondary outcome variables.

\section{Statistical Analysis}

All statistical analyses were performed using SPSS for Windows (ver. 20; IBM, Armonk, NY, USA). Continuous variables are presented as means \pm standard deviations, and categorical data are expressed as percentages and frequencies. Data were analyzed using the Shapiro-Wilk test to verify the normality of distribution. For normally distributed data, a paired t-test was used; otherwise, the Wilcoxon signedrank test was used. The outcome variables were compared between Tests 1 and 2, and p-values $<0.05$ were considered statistically significant.

\section{RESULTS}

\section{Participants' Characteristics}

Thirty-eight medical doctors from the CPR team were recruited. None of the eligible doctors had experienced any injury recently, and all agreed to participate in the study. 
Table 1. Demographic characteristics of participants

\begin{tabular}{ll}
\hline Characteristic & Data \\
\hline Gender & $35(92)$ \\
\hline Men & $3(8)$ \\
\hline Women & $28.2 \pm 3.5$ \\
\hline Age (years) & $1(3)$ \\
\hline BLS certification & $37(97)$ \\
\hline BLS Instructor & \\
\hline BLS Provider & $1(3)$ \\
\hline Position & $17(45)$ \\
\hline Attending physician & $20(52)$ \\
\hline Resident physician & $175.0 \pm 6.3$ \\
\hline Intern physician & $76.2 \pm 11.6$ \\
\hline Height $(\mathrm{cm})$ & $24.8 \pm 3.2$ \\
\hline Weight $(\mathrm{kg})$ & $45.9 \pm 3.3$ \\
\hline Body Mass Index $(\mathrm{kg} / \mathrm{m} 2)$ & \\
\hline Knee height $(\mathrm{cm})$ &
\end{tabular}

Data are expressed as $\mathrm{n}(\%)$ unless otherwise indicated.

BLS, basic life support.

Table 2. Comparison of chest compression: Test 1 (standing in a standardized in-hospital CPR set-up) vs. Test 2 (kneeling on the floor)

\begin{tabular}{|c|c|c|c|c|c|c|c|}
\hline \multirow[t]{2}{*}{ Parameters } & \multirow[t]{2}{*}{ Test $1(n=38)$} & \multirow[t]{2}{*}{ Test $2(n=38)$} & \multicolumn{2}{|c|}{ Paired Differences } & \multirow[t]{2}{*}{$\mathbf{t}$} & \multirow[t]{2}{*}{ df } & \multirow[t]{2}{*}{ p-Value } \\
\hline & & & Mean & SD & & & \\
\hline $\begin{array}{l}\text { Number of } \\
\text { compressions } \\
\text { (numbers) }\end{array}$ & $237.6 \pm 20.8$ & $242.2 \pm 25.2$ & -4.6 & 14.9 & -1.914 & 37 & $0.063^{*}$ \\
\hline $\begin{array}{l}\text { Average depth } \\
(\mathrm{mm})\end{array}$ & $53.1 \pm 4.3$ & $52.6 \pm 4.8$ & 0.5 & 3.6 & 0.854 & 37 & $0.398^{*}$ \\
\hline $\begin{array}{l}\text { Average rate } \\
\text { (numbers/min) }\end{array}$ & $116.4 \pm 10.2$ & $119.1 \pm 12.4$ & -2.7 & 7.3 & -2.284 & 37 & $0.028^{*}$ \\
\hline $\begin{array}{l}\text { Percentages of } \\
\text { complete release } \\
(\%)\end{array}$ & $81.2 \pm 28.1$ & $73.4 \pm 34.5$ & N/A & N/A & N/A & N/A & $0.252 \dagger$ \\
\hline $\begin{array}{l}\text { Percentages of } \\
\text { adequate depth } \\
\text { achievement (\%) }\end{array}$ & $68.8 \pm 26.2$ & $65.2 \pm 29.2$ & N/A & N/A & N/A & N/A & $0.473 \dagger$ \\
\hline Flow time (\%) & $98.4 \pm 1.1$ & $98.6 \pm 0.7$ & N/A & N/A & N/A & N/A & $0.392 \dagger$ \\
\hline
\end{tabular}

* Statistical significances were tested using two-sided paired t-tests.

$\dagger$ Statistical significances were tested using Wilcoxon signed rank tests.

CI, confidence interval; N/A, not applicable.

p-values $<0.05$ are presented in bold.

Thus, none of the recruited team members were excluded. The demographic data of the participants are shown in table 1.

\section{Comparison of Chest Compression: Standing in a Standardized In-hospital CPR Set-up vs. Kneeling on the Floor}

The outcome variables measured in all tests are shown in table 2 . In all tests, the average depth of compression met the depth recommendations of recent $\mathrm{CPR}$ guidelines (50-60 mm). (2) No significant difference between Tests 1 and 2 was observed $(53.1 \pm 4.3 \mathrm{~mm}$ vs. $52.6 \pm 4.8 \mathrm{~mm}$, respectively; $\mathrm{t}=0.854, \mathrm{df}=37, \mathrm{p}=0.398$ ). However, the average compression rate in Test $2(119.1 \pm 12.4$ numbers $/ \mathrm{min})$ was slightly faster than the recommended rate (100-120 compressions/min) and differed significantly from that of Test $1(116.4 \pm$ 10.2 numbers $/ \mathrm{min} ; \mathrm{t}=-2.284, \mathrm{df}=37, \mathrm{p}$
$=0.028)$. No differences were observed in any other outcome variable.

\section{DISCUSSION}

Even though CPR is provided by experienced rescuers in hospitals, the chest compression performed may not meet the recommendations in CPR guidelines. (17) The main difference between in-hospital and out-of-hospital CPR is the height of 
the rescuer relative to the patient, because most in-hospital CPR is performed with the patient lying in bed. (3)

Handley wrote that two obstacles decrease the quality of in-hospital CPR, especially chest compression depth: (1) the use of a mattress, and (2) the height gap between the rescuer and patient. (3) Although many studies have attempted to solve those problems, no solution has been ideal.

In the current study, we focused on the standard CPR position (kneeling beside the patient) because only this position is described in the guidelines. (2) Assuming that the standard position is the best posture for chest compression, we tried to maintain, as much as possible, the same posture during in-hospital CPR, where the rescuer is standing. The results of several studies support this approach. (5-7)

We discovered that the range of the rescuers' knee heights was not large compared to the range of their total heights, suggesting that we could standardize the height gap between the bed and a step stool with reference to the rescuers' average knee height. Our results confirmed that our hospital CPR team members were able to provide high-quality chest compression in both set-ups. In other words, the quality of chest compression when using the standardized in-hospital CPR set-up, which was established with reference to the rescuers' average knee height, was similar to the qual- ity when kneeling on the floor. The only difference was in the average rate, which was slightly faster in Test 2 . However, we concluded that this difference was not clinically important, because spontaneous circulation is most likely to return at a compression rate of $125 / \mathrm{min}$, and the probability declines at higher rates. (18) The present study focused on the relationship between the height of the rescuer and the position of the patient. We confirmed that the standardized in-hospital CPR setup used in our study could eliminate one obstacle to in-hospital CPR. However, the problems arising from the use of a mattress were not solved, because we did not evaluate the effects of a mattress.

If our standardized set-up is combined with specialized mattress-related equipment-such as mattress compression covers with a vacuum pump, or air mattresses that can be deflated-clinicians and investigators may resolve the lack of high-quality inhospital CPR. $(19,20)$

Our study had several limitations. First, the results were obtained in simulation trials using a manikin. A human trial is needed to increase the strength of the evidence. However, we were unable to conduct a human trial. Second, our apparatus did not include a mattress. Average compression depth, as well as quality of other parameters, may be lower when the patient is on a mattress than when he/ she is on the floor. Relatedly, a mattress might be needed to prevent patient injury in a real CPR situation. Therefore, our set-up could not be applied in a real situation without modification. Further studies should simultaneously evaluate the effects of a mattress. Thirdly, only CPR team members were enrolled in this study; the compression quality of other rescuers may differ. In addition, most (92\%) of the participants were men. The inclusion of more women or less-well-trained rescuers may have produced different results. Finally, our study did not confirm the relationship between the range of rescuers' knee height and the range of their total height. If the relationship between knee height and total height differs by country, the result of this study may not be relevant in other countries. Further study is needed to confirm this problem.

\section{CONCLUSIONS}

In conclusion, the quality of chest compression in the standardized in-hospital CPR set-up, which referenced the rescuers' average knee height, did not differ from that achieved when the CPR was performed while kneeling on the floor.

\section{REFERENCES}

1. Soar J, Nolan JP, Bottiger BW, Perkins GD, Lott C, Carli P, et al. European Resuscitation Council Guidelines for Resuscitation 2015: Section 3. Adult advanced life support. Resuscitation 2015;95:100-47.

2. Perkins GD, Handley AJ, Koster RW, Castren M, Smyth MA, Olasveengren T, et al. European Resuscitation Council Guidelines for Resuscitation 2015: Section 2. Adult basic life support and automated external defibrillation. Resuscitation 2015;95:81-99.

3. Handley AJ. In-hospital chest compressions--the patient on a bed. Resuscitation 2012;83:795-6.

4. Perkins GD, Smith CM, Augre C, Allan M, Rogers H, Stephenson B, et al. Effects of a backboard, bed height, and operator position on compression depth during simulated resuscitation. Intensive Care Med 2006;32:1632-5.

5. Cho J, Oh JH, Park YS, Park IC, Chung SP. Effects of bed height on the performance of chest compressions. Emerg Med J 2009;26:80710.

6. Foo NP, Chang JH, Lin HJ, Guo HR. Rescuer fatigue and cardiopulmonary resuscitation positions: A randomized controlled crossover trial. Resuscitation 2010;81:579-84.

7. Lewinsohn A, Sherren PB, Wijayatilake DS. The effects of bed height and time on the quality of chest compressions delivered during cardiopulmonary resuscitation: a randomised crossover simulation study. Emerg Med J 2012;29:660-3.

8. Sherren PB, Lewinsohn A, Wijayatilake DS. Effects of bed height on the performance of chest compressions: clinical application of results. Emerg Med J 2011;28:171.

9. Oh J, Chee Y, Lim T, Cho Y, Kim IY. Chest compression with kneeling posture in hospital cardiopulmonary resuscitation: A randomised crossover simulation study. Emerg Med Australas 2014;26:585-90.

10. Oh JH, Kim CW, Kim SE, Lee SJ, Lee DH. Comparison of chest compressions in the standing position beside a bed at knee level and the kneeling position: a non-randomised, single-blind, cross-over trial. Emerg Med J 2014;31:533-5.

11. Edelson DP, Call SL, Yuen TC, Vanden Hoek TL. The impact of a step stool on cardiopulmonary resuscitation: a cross-over mannequin study. Resuscitation. 2012; 83: 874-8.

12. Random Sequence Generator. RANDOM.ORG. Available from URL: http://www.random.org/sequences/ (Accessed Aug 17 2015)

13. Hong JY, Oh JH, Kim CW, Kim SE, Lee DH, Shin JH. Effects of bed height on the performance of endotracheal intubation and bag mask ventilation. Signa Vitae 2016;12:47-51. 
14. Perkins GD, Kocierz L, Smith SC, McCulloch RA, Davies RP. Compression feedback devices over estimate chest compression depth when performed on a bed. Resuscitation 2009;80:79-82.

15. Oh JH, Kim CW, Kim SE, Lee DH. Does the bed frame deflection occur along with mattress deflection during in-hospital cardiopulmonary resuscitation? An experiment using mechanical devices. Hong Kong. J Emerg Med 2016;23:35-41.

16. Sample size estimation. Centre for Clinical Research and Biostatistics. The Chinese University of Hong Kong. Available from URL: http://www2.ccrb.cuhk.edu.hk/stat/Means.htm. (Accessed Jun 16 2015)

17. Abella BS, Alvarado JP, Myklebust H, Edelson DP, Barry A, O’Hearn N, et al. Quality of cardiopulmonary resuscitation during inhospital cardiac arrest. JAMA 2005;293:305-10.

18. Idris AH, Guffey D, Aufderheide TP, Brown S, Morrison LJ, Nichols P, et al. Relationship between chest compression rates and outcomes from cardiac arrest. Circulation 2012;125:3004-12.

19. Oh J, Chee Y, Song Y, Lim T, Kang H, Cho Y. A novel method to decrease mattress compression during CPR using a mattress compression cover and a vacuum pump. Resuscitation 2013;84:987-91.

20. Oh J, Kang H, Chee Y, Lim T, Song Y, Cho Y, et al. Use of backboard and deflation improve quality of chest compression when cardiopulmonary resuscitation is performed on a typical air inflated mattress configuration. J Korean Med Sci 2013;28:315-9. 